\title{
FRONTERA, PROCESOS MIGRATORIOS Y AUTONÓMICOS EN LA CONFORMACIÓN TERRITORIAL MAM: CAMBIOS Y PERSPECTIVAS
}

\author{
Border, Migratory and Autonomy Processes in Mam Territorial Conformation: Changes and Perspectives
}

\author{
Joaquín Peña-Piña \\ Andrés Fábregas-Puig
}

Resumen: El objetivo del presente artículo es analizar el proceso de conformación territorial de una comunidad indígena mam a partir de los procesos productivos, migratorios, políticos y autonómicos ligados a su cultura y etnicidad, en su contexto de frontera. El análisis muestra los cambios en las fronteras socioeconómicas y culturales, los procesos migratorios y sus avances en cuanto a participación en la política local. Al exterior, establece sus límites con otras comunidades, actuando como un frente de expansión mediante el control del territorio, utilizando como estrategia la búsqueda de la autonomía. La metodología se basa en el análisis demográfico y sociológico con datos de los últimos quince años. El estudio se ubica en una comunidad indígena de la zona alta de la región Soconusco, al sureste de México.

Palabras clave: frontera, migración, autonomía, territorio, etnia mam.

Abstract: The aim of this paper is to analyze the process of territorial formation of an indigenous community Mam, from production, migration, political and regional processes associated with their culture and ethnicity in the context of border. The analysis shows changes in the socioeconomic and cultural borders forced to migrate to the coffee plantations and later under the influence of international migration and participation in local political community. Outside, sets its boundaries with other communities, acting as a front for expansion by controlling the territory, using search strategy of autonomy. The methodology is based on the demographic and sociological analysis with data from the last 15 years. The studio is located in an indigenous community at the highland area of the Soconusco region, southeast of Mexico.

Keywords: border, migration, autonomy, territory, ethnicity Mam.

Joaquín Peña Piña, doctor en Ciencias en Desarrollo Sustentable por El Colegio de la Frontera Sur, México. Profesor de tiempo completo B en la Universidad Intercultural de Chiapas, México. Temas de especialización: migración, estrategias de reproducción social, indígenas y cambio social. Correo electrónico: joaquin_ecosur@hotmail.com.

Andrés Fábregas Puig, doctor en Antropología Social por la Universidad Iberoamericana, México. Investigador titular en el Centro de Investigaciones y Estudios Superiores en Antropología Social-Occidente, México. Temas de especialización: antropología regional, ecología cultural y fronteras. Correo electrónico: apfgup@gmail.com.
Enviado a dictamen: 25 de agosto de 2014. Aprobación: 10 de junio de 2015.

Revisiones: 2. 


\section{Introducción}

$\amalg$ l concepto de frontera en el marco de los procesos migratorios y sociales ha tenido permanentes implicaciones políticas, económicas, simbólicas y culturales, que son pertinentes para el análisis de la ocupación, conformación y control de un territorio. En el marco del proceso de globalización actual y ante la creciente desigualdad socioeconómica, los territorios han experimentado progresivos flujos migratorios que, dada su magnitud, están influyendo en las comunidades y en las fronteras identitarias de sus pobladores, así como en sus normas, costumbres y modos de vida.

La etnia mam es protagonista de estos procesos, y destaca en este análisis porque su población, aunque está ubicada en dos países, mantiene relaciones sociales, identitarias y territoriales a ambos lados de la frontera binacional entre México y Guatemala.

La frontera sur de México limita con Guatemala y Belice, y es lugar de asentamiento histórico, además de los mames, de otros grupos étnicos, como los akatecos, mochós, q'anjobales, jacaltecos y chujes (Hernández, 1998; Fábregas, 2012a y 2012b). Entre los territorios mexicanos ubicados en esta frontera se encuentra el Soconusco, la región que nos ocupa, donde se promovió la producción de café bajo el sistema de fincas desde finales del siglo XIX. En esa época, los indígenas de la Sierra y el Altiplano guatemalteco sólo podían asegurar su sobrevivencia migrando temporalmente a estas fincas cafetaleras, donde eran objeto de maltrato, discriminación y explotación. Más de un siglo después, la migración a las fincas aún se mantiene, pero durante las últimas dos décadas los destinos migratorios se han diversificado hacia el interior del país y Estados Unidos. A la par de este cambio migratorio, en la región ha mejorado la infraestructura en materia de caminos, salud y educación, lo que ha influido en la dinámica socioeconómica local, en las prácticas culturales e identitarias y en la participación política.

El objetivo del presente artículo es analizar el proceso de conformación territorial de una comunidad indígena mam a partir de sus procesos de transformación socioeconómica, cultural y política en un contexto de frontera. Se busca profundizar en los mecanismos de negociación y conflicto de una comunidad que, con tristeza, recuerda su pasado de pobreza, marginación y discriminación padecido en las fincas cafetaleras. Dicha situación ha experimentado una rápida transformación en las últimas dos décadas a partir de la migración internacional, el mejoramiento de la infraestructura de caminos y la generación de nuevas alternativas socioeconómicas, así como de los programas de desarrollo, salud y, en especial, de educación. Por ello, interesa articular y analizar dichos procesos desde el concepto de frontera y desde la forma en que se despliega su etnicidad, a partir de las estrategias migratorias y productivas y de los mecanismos de lucha, negociación y autonomía.

El estudio de caso corresponde a Pavencul, una comunidad indígena mam ubicada en los alrededores del volcán Tacaná, que mantiene vínculos con diversas comunidades de la misma y diferente naturaleza, dentro y fuera del territorio, así como dentro y fuera del país, lo que le ha conducido a mantener relaciones transfronterizas no sólo de carácter geográfico, sino también socioeconómico y cultural. Por comunidades de la misma naturaleza nos referimos a aquellas que, aun estando en frontera, presentan los mismos rasgos característicos de organización social, perfiles culturales en general e incluso idioma. Las comunidades de diferente naturaleza son las que muestran rasgos definitorios distintos. La frontera internacional que divide México de Guatemala influye en las diversas manifestaciones y estrategias de una comunidad que vive la frontera como límite o "muro", como la nombra la gente, para referir que ahí termina el territorio de un Estado nacional y empieza el de otro; o también la frontera como frente, es decir, como punto de partida para expandirse territorialmente apoyándose en diversas acciones socioeconómicas, políticas y culturales. Consideramos que la comunidad Pavencul despliega ambas características de acuerdo con las estrategias y mecanismos colectivos que le dan identidad y cohesión. Retomando el planteamiento de Armijo (2011), la frontera representa un límite con profundidad, un ámbito en donde el Estado se encuentra 
con la sociedad; de ahí la necesidad de entender el significado de vivir en las fronteras y su influencia en la conformación del territorio.

En este texto iniciamos con una breve revisión conceptual como preámbulo para el análisis de los hallazgos de investigación en la comunidad indígena mam de Pavencul. Posteriormente, se describen los antecedentes de la etnia mam en la Sierra del Soconusco y algunos aspectos socioeconómicos e históricos que abonan a su comprensión. Se continúa con el análisis de la conformación territorial de una comunidad mam a partir de sus relaciones sociales con las comunidades vecinas, mexicanas y guatemaltecas, y se analiza el papel de la migración nacional e internacional, que consideramos se enmarca como un frente de expansión en virtud de que los migrantes, al involucrarse en la vida social y económica, amplían su influencia en las comunidades de otras latitudes y territorios. Es decir, la comunidad mam considera su punto de destino como un territorio propio, estableciendo el mismo modelo de comunidad que en el territorio de origen. Finalmente, se analiza el proceso de búsqueda de lo que este grupo indígena entiende por autonomía, que es promovido desde la comunidad como parte de un creciente liderazgo de los actores locales, dirigido al fortalecimiento de su influencia en el territorio en el que vive.

El estudio es parte de un proyecto de investigación más amplio dirigido a la comprensión de la situación sociodemográfica de la población del Soconusco liderado por investigadores de El Colegio de la Frontera Sur desde 1996, que busca explicar diversos aspectos demográficos relacionados con los temas de fecundidad, mortalidad y migración en comunidades de diversos contextos socioculturales de Tapachula, en la frontera sur de México (Salvatierra, 1996). En la investigación sobre migración de población indígena mam, se identificó la diversificación migratoria hacia el norte del país y Estados Unidos, así como factores asociados que explican este cambio (Peña, 2000), como las estrategias de reproducción social de los grupos domésticos. Se relacionan la producción de café y la migración (Peña, 2004), el análisis multidimensional del fenómeno migratorio (Peña, 2006), las remesas familiares, el papel de las mujeres (Peña, 2002) y la división sexual del trabajo (Peña, en prensa), entre otros aspectos que han aportado un panorama del proceso migratorio en la población mam referida. Aspectos como la identidad, la organización social, la autonomía y los aspectos de frontera han sido observados, pero no estudiados ni publicados. La metodología de la mayoría de los trabajos se basa en datos sociodemográficos con aplicación de encuestas probabilísticas. Asimismo, se han utilizado técnicas cualitativas a partir de entrevistas a profundidad y de historias de vida de personajes clave. Se han consultado datos estadísticos y se cuenta con un diario de campo con evidencias derivadas de la observación, que dan cuenta de numerosos procesos sociales de la comunidad y la región de estudio.

\section{Marco conceptual}

Para la elaboración de este texto hemos usadola hipótesis fronteriza que conoce sus primeros planteamientos en un histórico texto de Frederick Jackson Turner, seguido de los trabajos posteriores de Owen Lattimore (1969; el texto original se publicó en 1956) y varios estudios contemporáneos que se citan a lo largo del trabajo. Los estudios de frontera se han caracterizado en general por su manejo en dos vertientes: la frontera como límite y la frontera como frente de expansión. En el primer caso, Frederick Jackson Turner (1979; la tesis se expuso por primera vez en 1891) parte de su interpretación del trazo de la frontera americana como una manera para desligarse de Europa y deshacerse de ese límite impuesto por su lugar de origen, pero ahora en el nuevo territorio donde la frontera viene a representar un frente para ocupar "la tierra vacía, la tierra de nadie", que además no toma en cuenta la existencia de un territorio ajeno con población autóctona local. Dicha situación promovió el dominio sobre un territorio mediante la colonización con una población denominada pionera bajo el supuesto de que los pioneros actúan libremente sin la intervención del Estado. Sin embargo, es poco probable que un Estado no esté ligado a un grupo de pioneros con poder político y económico, sobre todo 
cuando se busca la expansión, el dominio y la conquista de un nuevo territorio. Esta forma de ser del pionero, según Jackson Turner, posiblemente se vea reflejada en los territorios de destino así como en el propio, valiéndose de las reivindicaciones ante los grupos de poder y, de alguna forma, siguiendo las formas de actuar que han mantenido los norteamericanos en cuanto a la búsqueda de una estructura y cultura democrática (Fábregas, 2005).

En la expansión del territorio, la cultura es, quizá, la principal preocupación que se mantiene en los Estados nacionales que albergan en su territorio una población significativa de inmigrantes. Para evitar el establecimiento de nuevas fronteras culturales al interior de la sociedad receptora, se establecen normas dirigidas a regular el uso de la lengua nativa y la diversidad de expresiones sociales y culturales que despliegan dichos grupos migrantes. En este sentido, se podría decir que los migrantes actuales también se constituyen en grupos pioneros que, aunque no actúen dirigidos por el Estado, lo hacen bajo la influencia de la falta de oportunidades originadas por éste, en la búsqueda de condiciones de vida digna, tomando decisiones para organizarse en asentamientos y tratar de adaptarse estratégicamente a la cultura local, en tanto mantienen mecanismos de reconocimiento con sus grupos de referencia.

En el segundo caso, Lattimore (1969) establece como principio que "una frontera se crea cuando una comunidad ocupa un territorio". En esta tesis, la posesión del territorio involucra a la acción humana dirigida no sólo a su ocupación física, sino también al manejo y el control de todas sus actividades dirigidas al uso, manejo e interpretación de los recursos naturales, la producción local, los procesos de organización social, las normas de comportamiento, los aspectos culturales, la toma de decisiones colectivas y el manejo de la política, como mecanismos inherentes a toda comunidad que marca y conoce sus límites y fronteras.

En este sentido, la ocupación por los mames de la región de la Sierra y Soconusco tiene de origen una explicación sociohistórica derivada de la política liberal guatemalteca, que favoreció el proceso de migración y ocupación forzada hacia la frontera y el territorio mexicano de personas de este grupo étnico, que finalmente se asentaron en los alrededores del volcán Tacaná. De este modo, la población migrante de la actual Guatemala se fue asentando y constituyendo en comunidades, desplegando diversas estrategias para establecer sus fronteras en un territorio históricamente común, pero jurídicamente fragmentado por las fronteras nacionales.

Por su parte, Andrés Fábregas ha incursionado en los estudios de frontera desde 1970, reflexionando sobre la globalización (Fábregas, 2003), el colonialismo (Fábregas, 2012a), y aplicando el concepto de frontera en casos concretos, como el análisis de las conformaciones regionales en los Altos de Jalisco (Fábregas, 2010), entre otros. Su aporte desde la ecología cultural ha contribuido a la comprensión de los procesos socioculturales y su aplicación en campo. Otros autores han incursionado en el análisis de los procesos fronterizos, entre los cuales destaca Grimson (2005), quien a través de un análisis histórico argumenta que las fronteras representan un aspecto estratégico para la comprensión de los procesos contemporáneos. Este autor se centra en el estudio de las identificaciones, que llevan al estudio de los límites en un entramado de relaciones que suponen una situación de contacto, de frontera. Al estudiar los límites, continúa Grimson, podemos saber aquello que un grupo o una identificación incluyen y excluyen, así como los dispositivos a través de los cuales construyen esas diferencias. Como zonas de expansión y de límite, los grupos se reconfiguran para cumplir nuevas funciones en el orden regional, de tal manera que las comunidades fronterizas pueden ser agentes a través de los cuales se generan cambios sociopolíticos significativos, más allá de la comunidad fronteriza, donde se presenta una doble tensión al existir una frontera límite entre Estados nacionales y una frontera que representa un espacio flexible de articulación entre sistemas con dinámicas socioeconómicas diferentes. Por su parte, Nicole Diesbach (2002) aporta elementos para la integración de un nuevo paradigma y marca una diferencia entre los análisis sociohistóricos de la frontera propios de la ciencia, que considera externos, 
para dirigirse a un planteamiento interno del concepto de frontera desde la psicología, sustentado en un modelo integrador y holístico, que nos dirige a tomar conciencia y derribar primero nuestras propias fronteras internas que nos separan de otros seres y culturas, para construir una conciencia de unidad, una conciencia sin fronteras. Se trata de analizar la construcción de la frontera tanto externa como interna, para comenzar a abrir los sentidos hacia una nueva percepción y hacia un cambio en la visión de la realidad. La identidad de cada individuo depende del lugar donde éste traza la línea limítrofe, y se produce una crisis de identidad cuando no se puede decidir cómo ni dónde delimitar esa línea. El individuo crea fronteras psicológicas y de identidad que pueden desplazarse y expandir los límites de su propia identidad. El aporte de Grimson desde la psicología nos muestra que no existen fronteras naturales, sino que constituyen una conceptualización que nos ayuda a fragmentar y captar la realidad, de tal manera que las fronteras que seguimos trazando son obstáculos a la conciencia de unidad. Por ello, la frontera se presenta entonces como una posibilidad dual, dado que puede pensarse como muro divisorio o como tejido de relaciones.

Las diversas perspectivas teóricas sobre el concepto de frontera requieren analizarse en el marco de procesos concretos, considerando la diversidad del concepto así como las propias estrategias que los grupos sociales despliegan a la luz de las relaciones sociales. Este planteamiento es pertinente para el análisis desde diversas escalas de conformación territorial y en el estudio de los procesos fronterizos.

\section{Antecedentes}

La palabra mam significa "padre genérico o abuelo". La cultura mam tiene un origen milenario; es una de las etnias más antiguas de la región y su territorio se extendía desde gran parte de lo que actualmente se conoce como el Altiplano guatemalteco, en lo que hoy son los departamentos de San Marcos, Quetzaltenango, Totonicapán y Huehuetenango, hasta los actuales municipios mexicanos de Mazatán, Mapastepec,
Motozintla, Mazapa de Madero, Cacahoatán, Unión Juárez y Tapachula (Medina, 1993; Hernández, 1998).

A mediados del siglo XIX, el territorio mam sufrió grandes modificaciones a partir de la política liberal en Guatemala y México, influida fundamentalmente por la producción de café, lo que originó una nueva dinámica socioeconómica entre la población indígena, la mestiza y los emigrantes extranjeros (Castellanos, 2006). Desde tiempo antes, muchos indígenas asentados originalmente en la actual Guatemala fueron despojados de sus tierras y forzados a trabajar en las fincas cafetaleras donde se inició el cultivo del aromático, lo que promovió su huida hacia los despoblados de la Sierra de Chiapas y los alrededores del volcán Tacaná en territorio mexicano (Gutiérrez y Hernández, 2000). Años después surgió la necesidad de proveer de tierras y seguridad jurídica a los inversionistas nacionales y a los emigrantes extranjeros que buscaban asentarse en Chiapas, para lo cual se establecieron los límites definitivos entre México y Guatemala mediante el tratado binacional firmado en 1892 . Este hecho marcó el primer elemento de diferenciación de la misma etnia mam respecto a las nacionalidades guatemalteca y mexicana en un territorio históricamente común. La frontera entre ambos Estados nacionales creó una población fronteriza y fue factor de diferenciación a pesar de la intensa movilidad local y de los lazos sociales y familiares entre indígenas de ambos países.

El auge del café transformó la región y ello explica los acelerados cambios socioeconómicos de la época (Castellanos, 2006; Pohlenz, 1995), que no reportaron mayor beneficio para los pobladores locales, quienes durante décadas fueron explotados y tratados como esclavos por las clases dominantes (Martínez, 1994), que fortalecieron las fronteras culturales como factor de diferenciación y desigualdad.

Durante el periodo postrevolucionario mexicano, el proceso de la Reforma Agraria en Chiapas hizo posible la expropiación de tierras a un gran número de finqueros. Así, los indígenas recibieron tierras para constituirse en ejidos y Pavencul fue uno de los primeros que se fundó en la región, en 1929. Esta situación incorporó un nuevo elemento en la conformación 
territorial con la transformación de los campesinos indígenas en campesinos ejidatarios. El establecimiento de las fincas de café y los ejidos en la sierra se articuló con la producción de maíz para el autoconsumo de los indígenas, y con la producción de café como producto comercial para exportación por parte de los finqueros, principalmente inmigrantes alemanes. ${ }^{1}$ A pesar de contar con sus propias tierras ejidales, el proceso de Reforma Agraria fue muy doloroso en la conformación del territorio e identidad mam ya que, al ubicarse en la frontera, se promovió con violencia una política de castellanización y prohibición del vestido y la lengua propia porque se buscaba "mexicanizar" la frontera nacional. Dicha situación implicó un ataque a su identidad, creando artificialmente una nueva población fronteriza despojada de su cultura. La intervención de las instituciones del Estado mexicano explica la situación fronteriza en relación con el objetivo de promocionar y consolidar el Estado nacional, apoyándose en instituciones como la escuela y en algunos programas culturales y de alfabetización del gobierno (Hernández, 2006).

En estos antecedentes se advierte la vulnerabilidad de la comunidad indígena mam, que no ejercía control sobre su propio territorio, cuyos pobladores contribuyeron al crecimiento económico del Soconusco sin beneficiarse de la riqueza y el desarrollo de la región, situación que se observa en la marginación actual de las comunidades de la Sierra y, en general, de otros grupos indígenas de la frontera. Si bien el Soconusco representa el mayor centro de desarrollo económico de la entidad, la población indígena mam de la parte alta del Soconusco y la Sierra presenta los más altos índices de marginación y pobreza (INEGI, 2010), y la comunidad de Pavencul es, en la actualidad, una de las más representativas de esta región.

\section{Pavencul: partiendo el bejuco}

El nombre de esta comunidad indígena mam proviene de una vieja historia: cuando una familia de Pavencul construía su casa, el suceso familiar trascendía a la comunidad. Los vecinos, como parte de un trabajo colectivo solidario, ayudaban en la construcción de las paredes de adobe y de los techos, que se tejían con pajón, un zacate que crece en macollos. Los racimos de pajón se amarraban con un bejuco conocido en la lengua mam como cul; éste tenía que cortarse (pavin) en pequeñas tiras para amarrar los racimos de pajón en los techos. El nombre de Pavencul deriva de esta actividad que se realizaba cotidianamente en el pasado, pavin y cul, partiendo o cortando el bejuco. La actividad concluía con una convivencia colectiva de las familias participantes en la que el dueño de la casa invitaba a comer. Desafortunadamente, esta costumbre casi ha desaparecido porque las casas ya no se construyen de adobe y pajón, sino que ahora dominan las de tabicón, mampostería y techo de lámina.

El ejido Pavencul se ubica en la parte alta del municipio de Tapachula y cuenta con una superficie aproximada de cuatro mil hectáreas (ver mapa 1). Limita al noreste con el cantón Villaflor, del vecino departamento de San Marcos, Guatemala. En territorio mexicano, al norte limita con Aquiles Serdán (Motozintla), al este con Tecoitac y Agua Caliente (Cacahoatán), al oeste con Toquián Grande (Tapachula) y al sur con Chanjalé Salchiji (Tapachula), entre otras comunidades de menor magnitud. El ejido conforma una cuchilla estratégica que conecta varios municipios mexicanos con la nación vecina en un breve espacio. En 2002 el ejido estaba organizado en ocho barrios - Pavencul, La Cueva, Bijahual, Carrizal, Buenavista, Pinal, Vega Los Molinos y Vega Malacatepero en 2012 se agregaron otros tres - Frontera 20 de octubre, Milenio Las Flores y Aguacaliente-, de modo que su población total en 2010, según datos censales, era de 4055 habitantes (INEGI, 2010).

El paisaje del territorio es accidentado y típico de la Sierra, y su altitud se extiende desde los 1200 hasta los 2350 metros sobre el nivel del mar, lo que da lugar a variaciones ecológicas y productivas, y define al mismo tiempo otras fronteras ecológico-culturales. En la parte media del ejido prevalece el clima templado con potencial para el cultivo del maíz mediante el sistema frijol-calabaza-chilacayote, la crianza de aves de corral, así como para la producción de hortalizas, 
que por lo general se siembran en los alrededores de la casa. En la parte más alta y fría del ejido se cultiva papa, haba y trigo, mientras que en la parte más baja y cálida se siembran café y otros productos, como el plátano y la naranja. Independientemente de estas diferencias ecológicas y culturales, una característica común a todas las comunidades rurales de las partes media y alta de Tapachula es la experiencia de trabajo en las fincas cafetaleras del Soconusco. Para entender el proceso de cambio en el territorio mam, se efectúa una segmentación en tres etapas históricas, que constituyen a su vez diversos parteaguas en la vida comunitaria de Pavencul en sus casi 85 años de existencia:

\section{Primera etapa (1929-1970)}

Corresponde básicamente al trabajo realizado en las fincas cafetaleras y no se producen cambios en la situación socioeconómica de marginación y pobreza en el ejido. Durante esos cuarenta años, las comunidades de la Sierra migraban a las fincas cafetaleras como única estrategia de subsistencia y no recibían apoyo de programas gubernamentales para cubrir sus necesidades básicas, además de que no gozaban de derechos como población indígena. En la historia oral reiteradamente se escuchan las condiciones de sufrimiento y marginación experimentadas en las fincas.

\section{Segunda etapa (1970-1992)}

En las dos décadas de este periodo destaca la introducción y apropiación del proceso productivo del café en Pavencul, con sus implicaciones en el proceso de acumulación y diferenciación socioeconómica de los grupos domésticos y en la dinámica comunitaria y regional. En 1970 inició la producción de café en una pequeña fracción de este ejido que contaba con condiciones ambientales para la producción del grano, específicamente en la parte más baja y cercana a las fincas. La mayor parte de la población se mantenía bajo condiciones de precariedad, pero fueron surgiendo algunos ejidatarios con cafetales que, aunque tenían una baja producción, ésta constituía un elemento suficiente para su diferenciación entre la población. La nueva coyuntura fue conformando una nueva frontera identitaria basada en el prestigio que fueron adquiriendo los poseedores de cafetal. Ante las deudas y los escasos ingresos derivados del trabajo en las fincas cafetaleras de la mayoría de la población, los ingresos por la producción local de café, aun siendo mínimos, contribuían a la acumulación, a la diferenciación y a los cambios en la dinámica socioeconómica al interior del ejido.

En un estudio realizado en Pavencul (Peña, 2000), al identificar los factores determinantes asociados a la migración se encontró que la posesión de parcelas hasta de una hectárea, la producción de café menor a dos quintales y la falta de ingresos económicos no agrícolas constituyen los principales factores de la migración. Aunque el estudio se realizó en una época más reciente y bajo otras condiciones, su aporte abona a la influencia de los procesos locales en el cambio y diversificación de los destinos migratorios que durante décadas sólo se dirigían a las fincas cafetaleras. Así se observa que, entre 1970 y 1990, la producción de café favoreció la posibilidad real para abandonar la migración a las fincas y experimentar nuevos destinos fuera del estado de Chiapas, ya que dicha experiencia extrarregional demandaba más recursos económicos y una mayor preparación escolar como parte de los costos de la migración. La nueva dinámica económica y el cambio social en este periodo generaron ingresos adicionales en las familias por la producción de café, así como por la recepción de remesas migratorias desde los destinos extrarregionales, lo que originó diferencias entre la población con migrantes locales y con migrantes extrarregionales (Peña, 2006).

El año 1990 constituye un parteaguas en la región y en la comunidad de Pavencul con la llegada de programas de desarrollo por parte del Estado en materia de infraestructura, educación y salud (Peña, 2005), pero sobre todo por la generación de nuevas expectativas de desarrollo y porque inició un proceso de lucha como pueblo indígena, históricamente rezagado, de modo que comenzó a aflorar en su discurso un mayor espíritu de lucha para combatir su situación de pobreza 
y marginación. Esta coyuntura fue generando una nueva conciencia y comenzó una nueva etapa en la que se observa la consolidación de nuevos liderazgos que incursionaron en la organización política para demandar apoyos gubernamentales y gestionar el control y reapropiación del territorio. Las implicaciones de este proceso influyeron en el reacomodo de las fronteras económicas, sociales e identitarias en la comunidad.

\section{Tercera etapa (1992-2012)}

Es un periodo que se caracteriza por la consolidación de la migración internacional, una creciente participación de los jóvenes, el refuerzo de la modernización de la comunidad a partir de las políticas públicas y la generación de nuevas expectativas. Inició una lucha que pretendía la formación de un municipio autónomo. Asimismo, se aceleraron los procesos de cambio social y de transformación socioeconómica a partir de los ingresos derivados del café, las remesas migratorias y otras actividades económicas, así como del mejoramiento de la infraestructura de salud y educación. La migración nacional e internacional se consolidó como la principal estrategia económica de la comunidad. En este periodo se produjo un cambio migratorio generacional con la creciente participación de varones y mujeres jóvenes que ya contaban con una mayor escolaridad que sus padres. La experiencia migratoria extrarregional ha influido en el modo de vida de los hombres y mujeres jóvenes, quienes se constituyeron en un grupo destacado en el cambio de la economía e identidad mam.

Por otra parte, Pavencul tomó una posición más combativa a partir de la influencia del levantamiento zapatista de 1994, con su propuesta de defensa de los derechos indígenas, y la comunidad desplegó una actitud poco dispuesta a mantenerse en la marginación y en la desigualdad económica que aún caracteriza a la región. Con la afluencia de ingresos económicos, la diversificación de las actividades productivas en el ejido y una nueva visión del desarrollo local, se fortalecieron los mecanismos de demanda y negociación con el
Estado en torno a su reconocimiento como pueblo indígena, al acceso a recursos y a la toma de decisiones a nivel municipal y estatal. Una vez identificadas las transformaciones sociales expuestas, se analizará la situación de las comunidades en su territorio a partir del concepto de frontera como límite, entre comunidades de la misma y de diferente naturaleza (Lattimore, 1969), en la región mam de estudio (ver mapa 1).

\section{La frontera como límite entre comunidades de la misma naturaleza}

Por sus antecedentes históricos y étnicos, en la frontera México-Guatemala se identifican varias comunidades de la misma naturaleza que cuentan con características socioeconómicas, culturales y ambientales similares. La línea fronteriza marca un límite entre los barrios Frontera 20 de octubre, Pinal y Buenavista, del ejido Pavencul, con el cantón Villaflor de San Marcos, Guatemala. Los Estados nacionales establecieron su límite fronterizo desde hace más de un siglo, pero no opera estrictamente en el territorio mam, con una población indígena y un pasado comunes, conformado por una población fronteriza con una fuerte relación social y reconocimiento mutuo. En este sentido, se consideran como comunidades de la misma naturaleza por la semejanza de los elementos que los unen en torno a vínculos sociales, económicos y culturales, manifestados en una estrecha relación familiar, social y productiva, que es muy intensa y persiste a ambos lados de la frontera. Estos elementos se han identificado mediante observaciones de campo durante los últimos quince años.

Por lo general, las comunidades en la frontera sur cuentan con escasa infraestructura y alta marginación a ambos lados de la línea. Su relación cultural como parte de la misma etnia favorece la dinámica fronteriza de trabajo y colaboración. Un ejemplo de esa relación se observa cuando las familias de la aldea Villaflor solicitan la anuencia de la comunidad para avecindarse en Pavencul y adquirir su propio lote en territorio mexicano, establecer un negocio o inscribir a sus hijos en las escuelas de educación básica del ejido con el aval 
de las autoridades ejidales. De igual forma, la unión de parejas se da sin diferenciar su procedencia, ya que prevalece la identificación étnica sobre la nacionalidad.

Hasta el año 1990 la zona alta de Tapachula no contaba con caminos y presentaba índices de marginación altos, motivo por el cual las relaciones sociales, económicas y culturales en esas comunidades guatemaltecas y mexicanas eran muy cercanas. En la interacción de las comunidades de ambos países destaca el cruce fronterizo Niquivil-Chehuaté, importante paso entre Motozintla y la ciudad de Tacaná, en el vecino departamento de San Marcos, Guatemala. Ante la ausencia de vías de comunicación, había un amplio tránsito de personas a pie y de arrieros con bestias cargadas de mercancías; los arrieros cumplían una función social muy importante en el intercambio de mercancías y en la socialización de la región. Durante muchos años, la compra de víveres, herramientas de trabajo, láminas para construir techos y otros materiales se realizaba en Tacaná, algunas veces en Motozintla y, en menor magnitud, en Tapachula.

El tránsito a Tacaná marcó toda una tradición comercial desde Pavencul favorecida por el tipo de cambio monetario hasta la década de 1980 (ver gráfica 1). La ventaja de la moneda mexicana fue disminuyendo entre 1985 y 1995 por la inestabilidad y la devaluación del peso mexicano respecto al quetzal, y de éste respecto al dólar, como resultado de la recesión y la crisis económica que se vivían a nivel nacional y mundial, aunque para entonces ya se venía construyendo el camino de terracería entre Tapachula y Motozintla pasando por Niquivil.

En relación con la comunicación telefónica, en 1996 se instaló una caseta de Telmex en la cabecera ejidal de Pavencul alimentada con energía solar. Durante varios años fue el único medio para comunicarse con los migrantes, de modo que tanto mexicanos como guatemaltecos que acudían al lado mexicano se congregaban y platicaban en los alrededores de la caseta mientras esperaban su turno. Desde el año 2000, la región alta de Tapachula ya contaba con servicios de telefonía celular proporcionados por Telcel, pero la señal sufrió un bloqueo a partir de la instalación de antenas en Chehuaté de las compañías guatemaltecas Tigo y Claro, que paradójicamente pertenecen al mismo dueño de Telmex, por lo que en adelante la población de Pavencul tuvo que cambiar de la compañía mexicana a la guatemalteca, aun viviendo en territorio mexicano.

En el aspecto cultural, una vieja tradición originada hace más de cuatro siglos en esa región es el culto y peregrinación al santuario del Señor de Esquipulas en Guatemala, el llamado Cristo Negro, que se celebra durante la primera quincena de enero y en el que participan numerosas familias tanto de México como de Guatemala. El culto al Cristo Negro se difundió por Mesoamérica y su origen prehispánico se relaciona con deidades cuyo color distintivo era el negro (Navarrete, 2010). Con motivo del año nuevo, otra expresión cultural entre la población fronteriza como parte de la identidad mam es la visita a la cúspide del volcán Tacaná, donde se reza en lengua mam, se prenden velas, se convive y se pide por la familia (Mejía, 2010). Tras el ritual se acostumbra en grupos comer tamales, acompañados con ponche de piña y aguardiente, a la venta en múltiples puestos comerciales improvisados. El paisaje desde ese punto es imponente, ya que se observa por completo el territorio mam y se distinguen la línea fronteriza y las comunidades de Niquivil y Chehuaté, así como las ciudades de Tapachula y Tacaná.

En relación con la religión, en territorio mexicano predomina la católica con más del $80 \%$ de la población, y en Guatemala la religiosidad protestante. Los protestantes mexicanos tienen una fuerte relación con sus similares de Guatemala porque, según afirman, la Iglesia está mejor organizada. Al respecto, un indígena presbiteriano de Pavencul comentó: “Allá en Guatemala está más desarrollada nuestra iglesia, los templos tienen centros de formación y hasta tienen radiodifusoras" (L.G., 23 años, soltero). De acuerdo con Robledo (2013), los misioneros presbiterianos desarrollaron un fuerte movimiento religioso en la Sierra y lograron fundar en 1920 la Iglesia presbiteriana en Mazapa de Madero, desde donde se difundió a Tapachula y el Soconusco. Por otra parte, esta Iglesia defendía el uso de la lengua mam, en contraste con la imposición del castellano y la 
prohibición del mam por parte del gobierno en la época de la Reforma Agraria.

No obstante que la población protestante presbiteriana y adventista, entre otras, es una minoría en relación con la católica en México, desde 1998 ha aumentado la diversidad y se han hecho presentes otras corrientes religiosas no católicas, como la Iglesia de Pentecostés, la Luz del Mundo, la religión evangélica, la bautista y los testigos de Jehová. Esta diversidad religiosa no ha sido motivo de conflictos en la comunidad, además de que la gente no rehúye el cumplimiento de los cargos comunitarios, ya que esas diferencias se suavizan en el marco de la etnicidad y la comunalidad a través del servicio comunitario, el apego a la tierra y el reconocimiento a la autoridad y a la identidad indígena (Regino, 2002), lo que contribuye a la convivencia y a una participación plena. En Pavencul, el liderazgo y el poder político lo ejercen principalmente un grupo de indígenas católicos y presbiterianos, quienes han desarrollado una intensa actividad política dentro y fuera de la comunidad, además de contar con un estatus económico favorable debido a que se dedican a actividades comerciales, como la producción de café, y han sido pioneros en la migración hacia destinos internacionales.

Por su parte, la comunidad protestante fronteriza organiza temporalmente jornadas de proselitismo religioso casa por casa en la región apoyándose en las radiodifusoras guatemaltecas, como la denominada "Fuente de vida", ubicada en Chehuaté, Guatemala, que desde este lugar fronterizo difunde música y cantos con mensaje religioso y envía oraciones a los feligreses de ambos lados de la frontera, además de funcionar como escuela de formación cristiana cuyo objetivo es difundir la palabra de Dios y promover encuentros juveniles en los que conviven jóvenes de ambas nacionalidades.

Desde el punto de vista ambiental, la ecología cultural y el ambiente natural son similares en la frontera de esta zona. En la Sierra existen variaciones orográficas que permiten descubrir una ecología cultural diversificada, pero a la vez complementaria, entre las comunidades fronterizas. La ecología cultural del lado mexicano permite el cultivo de productos basados en el sistema maíz-frijol-calabaza-chilacayote principalmente, asociado a las hortalizas $y$, en algunos casos, al café, mientras que en las comunidades del lado guatemalteco, por encontrarse a una mayor altitud, se producen más la papa, el trigo y el haba.

Se observan otras fronteras desde la ecología cultural que permiten una diferente vocación productiva y la posibilidad de un intercambio complementario de productos. En este aspecto, la lengua es el elemento más destacado en la identidad mam de la región. Aunque se prohibió su uso desde la década de 1930, en la actualidad se recrea de manera más ritual y familiar que en el espacio público, donde la lengua franca es el español. En el caso de la lengua mam, gran parte de la gente dice que la entiende, pero que no la habla; sin embargo, en realidad la lengua indígena se habla en las asambleas ejidales y en la iglesia, lo que indica que sigue presente en la vida comunitaria. Por su parte, la vestimenta ya se perdió entre los varones, quienes recuerdan el uso de la camisa y el calzoncillo de manta, además de una faja roja y sombrero; el atuendo tradicional de las mujeres se mantiene entre las más ancianas y consiste en un enrollado tejido multicolor, con una blusa y faja. Sin embargo, la mayoría de la población utiliza la vestimenta ladina. Recientemente, un grupo de jóvenes del ejido se organizaron para promover el uso de la lengua y el vestido a través de una página de facebook denominada "Ruta indígena mam" desde donde promueven su cultura.

En una zona históricamente marginada y ubicada en los límites de la nación, la identidad emerge ante el conflicto y la negociación con el Estado. La etnicidad, bajo esas circunstancias, ha permitido suavizar las diferencias de género y estrato en la comunidad para actuar como un frente común y reivindicarse como etnia. Al respecto, la gente participa de manera activa en el cumplimiento de cargos y en la organización social de la comunidad, de modo que continuamente gestionan demandas ante el gobierno local, con un respaldo pleno a las autoridades, y las diferencias de estrato y género se pasan por alto. La observación participante durante varias temporadas de campo ha permitido reunir evidencias para sostener esta afirmación. La situación 
anterior ha facilitado que la comunidad de Pavencul se haya consolidado como un frente de lucha, que ha pasado de la exclusión a la política, con vínculos entre las principales comunidades aledañas, como Toquián Grande y Chanjalé-Salchijí (Tapachula), Aquiles Serdán y Niquivil (Motozintla) y Agua Caliente y Tecoitac (Cacahoatán), por nombrar sólo las más importantes.

Pavencul es la comunidad más representativa de la Sierra por su extensión, el tamaño de su población, su liderazgo en la región y su lucha constante con las autoridades locales y estatales. Desde 1990 ha luchado junto con otras comunidades mames por sus derechos como pueblo indígena, ya que, de acuerdo con la política vigente, la adscripción indígena constituye una condición necesaria para acceder a recursos y a programas de desarrollo. Pavencul se ha ganado el reconocimiento a un liderazgo en la región a partir de sus negociaciones con las autoridades municipales y estatales, que no han estado exentas de confrontación, y que han contribuido a fortalecer su identidad como etnia y a estrechar una lucha solidaria con otras comunidades. Además, existe un intercambio de trabajo colaborativo, de productos agrícolas y de servicios, y se organizan actividades conjuntas a lo largo de la Sierra. Las autoridades de diversas comunidades mantienen una relación estrecha y están al tanto de los asuntos y problemas de la población.

La vigencia de la etnicidad se observa entre los migrantes a destinos internacionales o nacionales, ya que el simple hecho de pertenecer al pueblo mam y su región es razón suficiente, por ejemplo, para enviar remesas con aquellos que retornan, aunque no sean conocidos por los familiares a quienes se dirige el recurso, lo que reafirma el peso de la etnicidad como mecanismo de identificación. En ese caso, basta decir a los familiares que enviaron remesas con cierta persona de alguna comunidad cercana para que acudan a recuperar el dinero enviado. Lo mismo sucede en los lugares de destino migratorio, donde los jóvenes con frecuencia eligen pareja entre personas de la misma región o ejido, lo que permite fortalecer las relaciones sociales y familiares en el territorio mam.

\section{La frontera como límite entre comunidades de diferente naturaleza}

Se considera que las comunidades de distinta naturaleza son aquellas en las que se observan ecologías culturales diferentes y marcan sus fronteras identitarias. Entre ellas destaca la relación de la población indígena con otros grupos sociales, como los dueños de las fincas, quienes los explotaron y maltrataron durante décadas, los políticos mestizos, que los utilizan en sus campañas, y otros grupos sociales mestizos e indígenas no vinculados a la cultura mam.

Elvaloreconómicodelaromático, su comercialización y exportación detonaron una transformación notable en la región al generar una gran riqueza entre los grupos de poder. En todo ese proceso, las diferencias notables en las ecologías culturales se complementaron ya que, mientras las comunidades indígenas en la zona alta se mantenían con una economía de subsistencia basada en el sistema maíz-frijol-calabaza para el autoconsumo, en las fincas se producía comercialmente el café para la exportación; los trabajadores indígenas, al regreso a sus comunidades, se llevaban productos de la zona caliente, como panela, sal y fruta, además de maíz para cubrir el consumo familiar, de tal manera que se daban condiciones propicias para la interacción entre comunidades de una naturaleza diferente.

Son claras las distinciones en la naturaleza de estas comunidades, donde está implícita la estructura de poder que condujo a relaciones desiguales. Desde lo étnico, son recurrentes los recuerdos de los indígenas de Pavencul y de la Sierra sobre el desprecio y el maltrato sufridos por su condición indígena: "[...] los finqueros nos trataban como querían y nos daban de comer lo que querían, así la pasábamos [...]" (P.L., casado, 36 años), "[...] los patrones nomás nos regañaban y por cualquier ramita rota ya descontaban un octavo de la cuenta, nos maltrataban y nos amontonaban en las 'galleras' [...]" (N.B., casada, 70 años, Pavencul). Aunado a ello, los indígenas no eran considerados sujetos de desarrollo por el Estado, que no les trataba como personas con potencialidades, sino únicamente como fuerza de 
trabajo que no requería de programas específicos ni de políticas públicas.

La fuerza de trabajo indígena no era suficiente para mantener las labores de cultivo y la pica de café en el Soconusco, por lo que se hizo necesaria la traída de jornaleros indígenas de Los Altos de Chiapas (INAREMAC, 1990): “[...] venía mucha gente de San Cristóbal caminando, hablaban diferente y se vestían diferente y siempre por cuadrillas de unas doscientas personas [...]" (A.V., casado, 65 años, Pavencul), y del Altiplano guatemalteco, de donde migraban miles de jornaleros al Soconusco (Martínez, 1994).

La situación de la migración a las fincas cafetaleras se transformó a partir del cambio a destinos extrarregionales, preferentemente hacia Estados Unidos, por la posibilidad de un mayor ingreso, un trabajo menos rudo, un mejor trato y la opción de establecer una nueva relación con otras comunidades, otras costumbres y otras culturas. El impacto de la migración extrarregional, nacional o internacional ha sido amplio, aunado a otros procesos productivos y sociales. Los migrantes indígenas, al llevar su cultura al "norte", de alguna forma expanden su influencia a otros territorios, al mismo tiempo que transforman el propio. La experiencia con otras comunidades a partir de la migración internacional contribuyó a generar una visión con nuevas estrategias de lucha para ser tomadas en cuenta en el desarrollo regional. La concertación con otros actores sociales, la gestión directa con funcionarios, los plantones ante el ayuntamiento de Tapachula, e incluso la retención de funcionarios en la comunidad, han sido algunas de sus estrategias. Esta lucha ha posicionado a Pavencul en la vanguardia de los procesos políticos y sociales de la región y constituye un referente importante en el análisis de esta zona fronteriza.

La relación entre indígenas mam y finqueros es un ejemplo claro del establecimiento de las fronteras como límite. La diferencia entre las ecologías culturales e identitarias de los dos grupos está claramente marcada, pero el antiguo poderío de los finqueros como productores únicos de café se ha diluido. Ahora, la cafeticultura ejidal forma parte de las estrategias de reproducción de las comunidades que, además de diversificar sus actividades económicas, se fortalecen con el ingreso procedente de las remesas migratorias; por ello, a diferencia de los finqueros, son menos vulnerables a los cambios del mercado internacional del café. Para los finqueros la producción de café está en crisis, mientras que para los jornaleros indígenas el café representa una estrategia y un ingreso más como productores minifundistas. En el ejido Pavencul, en 1998, el tamaño de las parcelas de cafetal era de 0.756 hectáreas, con una producción promedio de 5.4 quintales; en 2002, de 0.892 hectáreas y 6.5 quintales, mientras que en 2012 se incrementó a 1.2 hectáreas y 7.1 quintales. Cabe recordar que la zona cafetalera del ejido Pavencul es muy reducida, por lo cual el incremento se debe principalmente a que los ejidatarios compraron terrenos en ejidos y comunidades cercanas, es decir, que la producción de café se ha extendido fuera del ejido, a la vez que han mejorado su sistema de producción, distante aún del rendimiento comercial de las fincas, ubicado por arriba de los quince quintales por hectárea, pero de gran importancia como factor de acumulación y diferenciación económica.

En la actualidad, el control de las actividades en el territorio se ha fortalecido a partir de la participación de indígenas mam de Pavencul en la toma de decisiones desde el ayuntamiento municipal de Tapachula (20122015) para ocupar cargos públicos en una regiduría y la Secretaría de Asuntos Indígenas. Desde entonces, la lucha inicial dejó de ser sólo ejidal y comunitaria para extenderse a otras comunidades del territorio mam a partir de la participación y gestión política, lo que constituye un elemento a considerar en el control y apropiación del territorio desde su adscripción étnica. Esta nueva estrategia política de Pavencul lentamente se ha articulado con su quehacer, de modo que han logrado que políticas públicas y acciones de gobierno se dirijan hacia un desarrollo incluyente y participativo en las comunidades indígenas de la Sierra mediante la toma de decisiones colectivas, la planeación y la promoción del desarrollo regional. Todo ello ha contribuido a fortalecer el control del territorio a través de la gestión, la autogestión, la promoción de la cultura y las actividades productivas. 
En esta experiencia consideramos que se hace un uso político de la identidad en Pavencul como un elemento indispensable para acceder a recursos económicos y apoyos bajo el argumento de la preservación de la cultura mam, pero también se observa que un sector de la población desea integrarse a los mecanismos de organización social y a las actividades de la sociedad dominante mestiza. Lo anterior muestra cómo las comunidades desarrollan estrategias para reinventarse como indígenas con el objetivo de obtener recursos y mover sus fronteras de acuerdo con las estrategias y el proyecto colectivo. Esta situación es especialmente relevante entre los jóvenes, quienes han crecido con una mayor escolaridad, sin experiencia en el trabajo en las fincas y con nuevas expectativas fuera de la comunidad, ya sea para estudiar o para migrar a Estados Unidos.

\section{La migración internacional como frente de expansión de la comunidad indígena}

La migración es un elemento histórico en el ciclo de vida de las culturas. No se puede entender el contexto histórico actual de la población mam y la ocupación de su territorio sin la migración. Asentados principalmente en la actual Guatemala, los indígenas mam fueron forzados a migrar ante el despojo de sus tierras, cambiaron de asentamiento y migraron de forma temporal a las fincas cafetaleras durante más de sesenta años. Sin embargo, desde 1985 emigran también a destinos nacionales e internacionales. Antes de ese año, la magnitud de la migración a las fincas era muy cercana al cien por ciento y de tipo familiar (Peña, 2011), mientras la comunidad quedaba prácticamente abandonada.

Este proceso migratorio ha tenido diversos impactos. Mientras el trabajo en las fincas representaba una opción para la sobrevivencia, la migración a destinos extrarregionales significa un cambio estratégico para iniciar un proceso de acumulación y diferenciación socioeconómica, lo que ha marcado una diferencia entre migrantes locales y migrantes internacionales. Considerando las relaciones de intercambio económico, social y cultural a partir de la migración internacional, esta última representa una forma de expansión del territorio de los migrantes en los lugares de destino, donde la cultura mam y la cultura anglosajona interactúan. Si la migración implica relacionarse con otras normas, costumbres y prácticas diferentes a las del lugar de origen de los migrantes, entonces existe la posibilidad de que los mismos se vean en la necesidad de integrarse a la cultura local a través del tiempo, combinándola con su propia cultura de origen.

En este proceso no sólo se pueden traspasar y modificar las fronteras identitarias, sino que la cultura mam trasciende a la comunidad receptora. Así, como Frederick Jackson Turner explica al hablar de la expansión de la frontera americana, del mismo modo los migrantes mames en Estados Unidos, a través de su trabajo y el establecimiento de relaciones sociales y económicas, expanden su influencia para trazar nuevas fronteras en otro territorio. Los mecanismos colectivos de apoyo y solidaridad se fortalecen en el territorio de llegada y se van conformando redes sociales similares a las de la comunidad de origen.

En 1985inicióla migración extrarregional en Pavencul. Entonces, la magnitud de este tipo de migración no era mayor al 2\% de la población del ejido y sobre todo migraban varones adultos; sin embargo, los migrantes fueron ocupando espacios en ciudades importantes del centro y norte del país, como la ciudad de México, Guadalajara, Ciudad Juárez, Tijuana y Hermosillo, esta última como centro de trabajo de la agricultura de exportación del noroeste. Estos centros del norte del país se fueron consolidando como lugares de acogida de migrantes indígenas chiapanecos. Posteriormente, entre 1992 y 1998, la magnitud se incrementó hasta llegar al 5\% de la población, predominando la migración rural-rural, aunque algunas mujeres migraron como trabajadoras domésticas a las ciudades, iniciando así la migración rural-urbana. Los grupos indígenas comenzaron a cruzar la frontera norte hacia estados de la costa este de Estados Unidos para trabajar en el campo, en la agricultura comercial, y también en las ciudades, en el sector de los servicios y en las fábricas. Aproximadamente en 2005 la migración internacional experimentó un incremento notable al comenzar el relevo generacional, de los varones adultos a los jóvenes. 
Al inicio de la siguiente década, en 2012, la migración internacional se consolidó entre los jóvenes, mientras la migración a las fincas disminuía sensiblemente a menos del 20\% de los grupos domésticos. En esta nueva dinámica la mayoría sólo trabajaba por periodos cortos de algunas semanas, lejos de los tres a cuatro meses que permanecían en las fincas como parte de sus estrategias de sobrevivencia (Peña, 2004; Peña, 2005). Desde entonces, los jóvenes conforman el principal contingente migratorio que está marcando los procesos de cambio y transformación en la comunidad de origen, así como en las comunidades de destino (Peña, 2005a).

La expansión de las prácticas migratorias se ha consolidado durante los últimos veinte años (ver mapa 2), y en este proceso la comunidad de Pavencul se fue expandiendo desde lo local, hasta lo nacional, y de ahí a lo internacional, conformando ciertos espacios y ámbitos sociales con un carácter diverso e intercultural sin precedentes. Este paso de lo local a lo global causó un fuerte impacto en un inicio, ya que la gente trascendió más allá de las fincas: "[...] yo nada más conocía de la comunidad a la finca, y siempre me preguntaba iqué habrá después de las fincas?, ¿cómo serán las tierras?" (P.L., casado, 38 años, Pavencul). Lo anterior marcó la ruptura de las fronteras locales limitadas a la finca, para extenderlas al interior del país y a Estados Unidos. En este proceso se conformaron redes de apoyo que han extendido los vínculos fuera de la comunidad, al mismo tiempo que han disminuido sensiblemente los costos de la migración, lo que facilita la movilidad y la posibilidad de establecer relaciones sociales.

Tomando en cuenta las tendencias observadas, consideramos el proceso migratorio extrarregional y su diversificación en otros territorios como un frente de expansión de la comunidad que va más más allá de las fronteras de la misma. Los migrantes se arriesgan a dejar su comunidad y a iniciar un proceso de asentamiento y apropiación del territorio en los lugares de destino. En la práctica se establece la frontera como un frente, cuya situación depende de la permanencia, el vínculo con la comunidad de origen y el manejo de la ecología cultural y las relaciones socioeconómicas que se observan en los lugares de destino. En las primeras experiencias migratorias de los indígenas mam al norte del país sólo participaban varones adultos que mostraban un mayor apego a su comunidad, con pocos cambios en sus costumbres y en su personalidad, pero hoy en día la migración internacional la emprenden los jóvenes, quienes tienden a adquirir más fácilmente otras costumbres y normas sociales diferentes a las de la comunidad, lo que genera, en algunos casos, conflictos en la comunidad y al interior de las familias relacionados con la pérdida de normas tradicionales, como el respeto o la vestimenta, y el cambio en las formas de vestir y convivir, diferentes a las de la comunidad. Algunos jóvenes son más proclives a establecer su residencia definitiva en los lugares de destino, además de que hacen un uso importante de la tecnología de las comunicaciones a través de internet y el teléfono celular, lo que les permite fortalecer las relaciones sociales, además de estar en contacto con sus familias. Esto significa que los cambios derivados de la migración internacional encuentran diversas posiciones e interpretaciones con el retorno migratorio en términos de beneficios y limitantes. Por una parte, el proceso migratorio permite extender la influencia de la comunidad en los lugares de destino, de manera que actúa como un frente de carácter socioeconómico y cultural y, por el otro, introduce cambios en la propia comunidad.

\section{La autonomía como frente de expansión en la comunidad indígena de Pavencul}

Pavencul es una comunidad que fue utilizada durante muchos años por el PRI como partido dominante en las elecciones para obtener votos. Cansados de esa situación, en la década de 1990 la comunidad organizó una lucha política para hacer valer una serie de demandas y promesas incumplidas por los gobiernos anteriores, y dirigieron sus esfuerzos hacia la búsqueda de apoyos gubernamentales. En estos esfuerzos subyacían mecanismos de su etnicidad al actuar como grupo colectivo y refrendar su condición de indígenas para obtener recursos. En 1997 el gobierno estatal creó el Consejo Regional Indígena de la Micro-región Mam como un medio de enlace para los programas y proyectos específicos destinados a la población indígena de la 
Sierra. A pesar del discurso manejado por el gobernador en turno, Albores Guillén, no lograron nada en los tres años siguientes y hasta el término de ese gobierno. Como era de esperar, la población continuaba inconforme e inquieta, pero aun así los pobladores siguieron apoyando a los candidatos electorales municipales a cambio de apoyos y obras públicas. Mientras tanto, el ejido continuaba su transformación socioeconómica a consecuencia de la producción del café, la migración internacional y las remesas económicas, pero ahora, con jóvenes con estudios, demandaba empleos y apoyos para la producción agrícola local.

La lucha social de Pavencul tuvo continuidad durante el gobierno estatal de Pablo Salazar Mendiguchía y en septiembre de 2000, bajo la asesoría del grupo de productores de café Indígenas de la Sierra Madre de Motozintla (ISMAM) y las autoridades de Pavencul, se constituyó el Comité Pro Creación del Municipio Autónomo de Pavencul, bajo el manifiesto de que "les asiste la razón histórica, jurídica y política para lograr ese proyecto". Tomando como base la estructura territorial de la microrregión mam, el 12 de marzo de 2001 tres comunidades de la Sierra iniciaron el autodenominado proceso de "independización" de los ayuntamientos de Tapachula, Motozintla y Cacahoatán, dirigido a conformar un nuevo municipio autónomo, libre y soberano denominado Pavencul, debido a “[... el olvido en que las autoridades los han mantenido como pueblo Mam descendiente directo de la cultura maya, y porque se nos niega un trato digno y adecuado, ignorando nuestras necesidades de salud, vivienda y educación [...] y por no haber tenido hasta ahora un representante directo en los órganos de gobierno federal y estatal [...]" (Villalba, 2001a).

La reacción a este planteamiento fue inmediata y las autoridades correspondientes declararon que el gobierno de Pablo Salazar había dejado en claro que el proceso de remunicipalización iniciado por Albores Guillén había terminado, y que en este nuevo caso se harían a un lado: "[...] intereses creados de un capital político que los venía aprovechando en los procesos electorales y objeto de manipulación y coto de votos para los tres municipios que los gobiernan [...]" (Villalba, 2001b). Una demanda cumplida fue la carretera de terracería de Pavencul a Tapachula, gestionada durante el periodo municipal de José Antonio Aguilar Bodegas por parte del PRI a principios de la década de 1990, vía que favoreció la comunicación local con el exterior.

A pesar del desacuerdo, el gobierno estatal reaccionó favorablemente ante la nueva coyuntura política y social generada por Pavencul y creó un ambiente para el desarrollo de acciones específicas que se concentraron en el mejoramiento de la estructura comunitaria. Tan sólo en dos años, entre 2001 y 2003, fluyeron a la comunidad algunos apoyos que se tradujeron en acciones concretas, como la instalación de una oficina del Registro Civil, la construcción de nuevos caminos al interior del ejido y de una nueva casa ejidal, la ampliación de la telesecundaria, la pavimentación de las arterias principales de la cabecera ejidal y la edificación de una casa de cultura con equipo de cómputo. Posteriormente se construyeron el mercado y la escuela preparatoria estatal, se amplió la clínica y se le proveyó de ambulancia, se construyó una nueva agencia municipal, se instaló alumbrado público y se pavimentó la cabecera ejidal, así como la carretera en el tramo de Pavencul a Tapachula. Esta ampliación de la infraestructura y urbanización del ejido ocasionó que las autoridades municipales y estatales dejaran de considerar a Pavencul como una comunidad indígena, al asociar la marginación con la condición indígena, lo que hasta la fecha les ha limitado el acceso a programas y la afluencia de recursos, y a su vez ha generado inconformidad en la comunidad.

Más allá de los logros alcanzados, esta experiencia de lucha a través de la organización social de los grupos familiares y las instituciones locales muestra la conjunción de valores y prácticas de la acción colectiva de Pavencul que refrenda su identidad indígena; una comunidad mam que sigue luchando y consolidando los mecanismos de apropiación del territorio manifiestos en su organización interna y en la lucha política hacia el exterior, lo que le ha significado conformar un frente, una frontera más amplia con la mayoría de las comunidades de la zona alta de Tapachula. 


\section{Conclusiones: territorio y fronteras}

El proceso hasta aquí analizado da cuenta de la transformación y apropiación del territorio de una comunidad mam, y del cambio de sus fronteras identitarias, como primeras dimensiones de análisis de los procesos de transformación territorial. Si bien ninguna cultura permanece inmóvil, hay evidencias de una transformación multifactorial y de cambio social bajo la influencia de la dinámica comunitaria y global, pero también de otros procesos socioeconómicos, como la migración, los medios de comunicación y las políticas públicas. La comunidad de Pavencul ha forjado una posición política y social que continúa avanzando en el control de su propio territorio a partir de sus actividades económicas, sociales y culturales, lo que implica el trazo de nuevas fronteras. Ello ha conducido a reflexionar en torno a las fronteras identitarias; por un lado se encuentra el afianzamiento de su identidad mam mediante el reconocimiento de sus características como "gente de costumbre" (Bartolomé, 1997), con base en la acción colectiva y en su conformación territorial, entre la población adulta y, por otro lado, se observa el debilitamiento y la paulatina disolución de los mecanismos colectivos entre algunos jóvenes. Mientras los primeros reivindican su origen, los segundos ceden ante la modernidad y se integran a la sociedad dominante.

En este sentido, los jóvenes se han convertido en el motor principal de un cambio social acelerado que está influyendo en la transformación de las fronteras étnicas e identitarias que de manera clara caracterizan a la etnia mam, manifiestas en el cambio y conflicto de sus costumbres derivados de la migración internacional y de la relación con otras personas y modos de vida. La identidad se ha transformado con la adopción de nuevas costumbres que tienden a borrar de manera rápida, y aún poco visible para sus habitantes, las costumbres tradicionales y sus valores culturales. Por su parte, los adultos, que mantienen una fuerte identidad mam con normas consolidadas, así como una visión clara como grupo colectivo, trabajan actualmente en el fortalecimiento de las fronteras políticas, tratan de expandirse más allá de la comunidad y buscan la negociación con el Estado para fortalecer su gestión y la autonomía municipal, lo que les ha permitido tomar sus propias decisiones para el cumplimiento de sus demandas. Se considera un proceso de expansión porque la población tiene una influencia sobre el territorio que va más allá de su comunidad, al vincularse a la política e incidir en la gestión del presupuesto y en la toma de decisiones sobre los programas y políticas públicas.

La revisión de estos antecedentes muestra el manejo que una comunidad indígena ejerce sobre sus fronteras y formas de identificación y refleja sus límites, primero como grupo con sus diferencias internas, algunas ya expuestas, y posteriormente con los grupos que los rodean, recreando dicha identidad en relación con los otros. Así, el comportamiento de Pavencul como comunidad indígena mam parte de su propia reflexión como gente de "costumbre", con una identidad recreada en los mecanismos sociales y su identificación en el territorio a través de la lengua, el vestido, la producción y la organización social, la lucha política y la colaboración con otros actores.

El enfoque propuesto es propicio para analizar cómo una comunidad moviliza sus fronteras en función del proyecto colectivo; por una parte a través de sus relaciones sociales con los indígenas mames de Guatemala, con los ejidos y con las comunidades vecinas, y por otra parte a través de las relaciones de trabajo con los finqueros mestizos y extranjeros del Soconusco, así como el papel de la misma población a través de los procesos migratorios y autonómicos, que traza nuevas perspectivas en la movilidad de sus fronteras.

De acuerdo con Lattimore, las fronteras se establecen cuando una comunidad se asienta en un territorio, y se establecen los dos tipos de comunidad aquí mencionados, aquellas de la misma y las de diferente naturaleza. La necesaria interacción entre ambas a través de diversas estrategias permite el establecimiento de fronteras sociales e identitarias, mediadas por los procesos de transformación económica, cultural y política, con la influencia adicional de una frontera 
internacional como zona estratégica de los Estados nacionales.

Los resultados conducen a una discusión más profunda sobre el papel del territorio donde se recrean los procesos expuestos. Tanto la re-territorialización y la des-territorialización en torno a la migración y la autonomía, que influyen en el establecimiento y movilidad de las fronteras, serían ejemplos de estos procesos. En el caso de la migración, dirigida principalmente a la búsqueda de recursos económicos, también se ha convertido en un frente de expansión que implica el restablecimiento de la comunidad en el lugar de destino, en tanto que la autonomía busca extender su influencia social y política más allá de la comunidad para afianzar el control del territorio.

Ante esta situación, las fronteras, debido a la movilidad y el surgimiento de movimientos sociales, ya no definen un límite, sino que, de acuerdo con estrategias de los grupos sociales como la migración o la autonomía, se movilizan y se expanden. Bajo esta perspectiva, el concepto de frontera como límite requiere de una mayor revisión ya que su trazo no define necesariamente ese límite, a diferencia del enfoque de frontera como frente de expansión, que está mostrando un gran dinamismo en la actualidad como parte de los procesos de globalización que buscan flexibilizar y evitar el establecimiento de fronteras y que paradójicamente reafirman lo local e influyen en el control del territorio.

El análisis de la conformación territorial de una comunidad indígena mam a partir del concepto de frontera muestra las nuevas perspectivas de su aplicación como herramienta de análisis en los movimientos sociales, económicos, culturales y políticos contemporáneos.

\section{Notas}

1 Los inmigrantes alemanes se establecieron en el Soconusco gracias a la política de apoyo de los gobiernos liberales, pero especialmente durante el gobierno de Porfirio Díaz invirtieron su capital para obtener ganancias y estar al frente de innovaciones tecnológicas en la producción de café, a lo largo de varias generaciones. Para profundizar en el tema ver a Manuel López Echeverría (2013) y Germán Martínez (1994).

\section{Referencias bibliográficas}

Armijo Canto, Natalia (2011), "Frontera sur de México: los retos múltiples de la diversidad". En Natalia Armijo (ed.). Migración y seguridad: nuevo desafio en México. México: Colectivo de Análisis de la Seguridad con Democracia A.C., pp. 35-5l.

Bartolomé, Miguel Alberto (1997), Gente de costumbre y gente de razón. Las identidades étnicas en México. México: Siglo XXI Editores, Instituto Nacional Indigenista.

Castellanos Cambranes, Julio (2006), Caféy campesinos. Los orígenes de la economía de plantación moderna en Guatemala, 1853-1897. Madrid: Editorial Catriel.

Diesbach de Rochefort, Nicole (2002), "Frontera: ¿muro divisorio o tejido de relaciones?" En Estudios Fronterizos, vol. 3, núm. 5, pp. 9-42.

Fábregas Puig, Andrés (2003), "Las fronteras en un mundo globalizado". En LiminaR. Estudios Sociales y Humanísticos, vol. 1, núm. 1, pp. 6-17.

Fábregas Puig, Andrés (2005), "El concepto de frontera: una formulación”. En Alain Basail (ed.), Fronteras (des) bordadas. Ensayos sobre la Frontera Sur de México. México: Universidad de Ciencias y Artes de Chiapas, Juan Pablos Editores, pp. 21-52.

Fábregas Puig, Andrés (2010), Configuraciones regionales mexicanas: un planteamiento antropológico. México: CEDESTAB.

Fábregas Puig, Andrés (2012a), El mosaico chiapaneco. Etnografía de las culturas indígenas. México: Comisión Nacional para el Desarrollo de los Pueblos Indígenas, Delegación Chiapas.

Fábregas Puig, Andrés (2012b), "Fronteras y colonialismo: una reflexión desde la frontera México-Guatemala”. En Journal of Latin American and Caribean Anthropology, vol. 17, núm. 1, pp. 6-23.

Grimson, Alejandro (2005), "Fronteras, estados e identificaciones en el cono sur". En Daniel Mato (ed.). Cultura política y sociedad. Perspectivas latinoamericanas. Buenos Aires: Consejo Latinoamericano de Ciencias Sociales, pp. 127-142.

Gutiérrez Alfonso Carlos y Rosalva Aída Hernández Castillo (2000), Los mames. Éxodo y renacimiento. México: Instituto Nacional Indigenista. 
Hernández Castillo, Rosalva Aída (1996), "Entre la modernización y el museo: La construcción etnográfica de la cultura mam (1933-1968)". En Anuario de Estudios Indígenas, vol. 6, pp. 9-117.

Hernández Castillo, Rosalva Aída (1998), "Indigenismo y desarrollo en la frontera sur chiapaneca”. En Comercio Exterior, vol. 48, núm. 5, pp. 399-408.

Instituto de Asesoría Antropológica para la Región Maya, A.C. (1990), "Trabajo en las fincas. Prácticas de los tzotziles sobre las fincas cafetaleras de Chiapas". San Cristóbal de Las Casas, Chiapas: INAREMAC.

Instituto Nacional de Estadística, Geografía e Informática (INEGI) (2010), Censo Nacional de Población y Vivienda. México: INEGI.

Lattimore, Owen (1969), "The Frontier in History". En Robert Manners y David Kaplan (ed.), Theory in Anthropology. Chicago: Aldine, pp. 374-386.

López Echeverría, Manuel Efrén (2007), "Las fincas cafetaleras alemanas en el Soconusco: más de 150 años de experiencia”. En Manuel de Jesús Moguel Liévano (coord.), Reflexiones sobre experiencias de investigación en algunas organizaciones en Chiapas. México: Universidad Autónoma de Chiapas, Universidad Autónoma Metropolitana-Iztapalapa, pp. 6-20.

Martínez Velasco, Germán (1994), Plantaciones, trabajo guatemalteco y política migratoria en la frontera sur de México. México: Gobierno del Estado de Chiapas, DIF-Chiapas, Instituto Chiapaneco de Cultura.

Medina Hernández, Andrés (1993), “Los mames". En Víctor Manuel Esponda (comp.), La población indígena de Chiapas. México: Gobierno del Estado de Chiapas, DIF-Chiapas, Instituto Chiapaneco de Cultura.

Mejía Robledo, Cristian Nayeli (2012), "Tradición oral de los mames del volcán Tacaná de Chiapas: recuperación e interpretación de la narrativa oral". Tesis de licenciatura en Lengua y Literatura Hispanoamericana, Facultad de Humanidades de la Universidad Autónoma de Chiapas, Tuxtla Gutiérrez, Chiapas.

Navarrete Cáceres, Carlos (2010), "Esquipulas: origen y difusión de un Cristo negro en Mesoamérica". En $\chi$ Congreso Centroamericano de Historia. Universidad Nacional de Nicaragua, 12 al 15 de julio de 2010, Managua, Nicaragua, pp. 1-10.
Peña Piña, Joaquín y Austreberta Nazar Beutelspacher (2006),"Producción de café y migración laboral indígena mam en Chiapas: hacia un análisis multidimensional de las estrategias de reproducción". En Jurgen Pohlan, Lorena Soto y Juan Barrera (ed.). El cafetal del futuro. Realidades y visiones. Aquisgrán, Alemania: Shaker Verlag, pp. 447-458.

Peña Piña, Joaquín (2004), "Migración laboral de las mujeres y estrategias de reproducción social en una comunidad indígena mam de la Sierra Madre de Chiapas, México". Tesis de doctorado en Ciencias en Ecología y Desarrollo Sustentable, El Colegio de la Frontera Sur, San Cristóbal de Las Casas, Chiapas. Peña Piña, Joaquín (2004), "Migración, remesas y estrategias de reproducción. Mujeres esposas de migrantes y relaciones de género en la región indígena mam del Soconusco, Chiapas". En Blanca Suárez y Emma Zapata Martelo (coord.). Remesas. Milagros y mucho más realizan las mujeres indígenas y campesinas. México: Grupo Interdisciplinario Mujer, Trabajo y Pobreza, A.C., vol. II, pp. 33-76.

Peña Piña, Joaquín (2005a), "Migración indígena mam en la Frontera Chiapas-Guatemala". Ponencia presentada en el Seminario-Taller Migración Intrafronteriza en América Central, Perspectivas Regionales. Centro Centroamericano de Población, Universidad de Costa Rica, San José Costa Rica, del 3 al 5 de febrero de 2005.

Peña Piña, Joaquín (2005b), "Las políticas del Estado, cambio social y migración laboral". En Política y Cultura, vol. 23, pp. 25-42.

Peña Piña, Joaquín (2011), "La migración de mujeres indígenas en un contexto de frontera. Trayectorias laborales y sus aportes a la economía de los grupos domésticos y la comunidad". En Chiapas. Territorio, fronteras, migraciones, desarrollo. Visiones interculturales multidisciplinarias, vol. I. México: Universidad Intercultural de Chiapas.

Peña Piña, Joaquín (en prensa), "Procesos migratorios, división sexual del trabajo y participación de las mujeres". En Chiapas. Territorio, fronteras, migraciones, desarrollo. Visiones interculturales multidisciplinarias, vol. II. México: Universidad Intercultural de Chiapas, CLACSO. 
Peña Piña, Joaquín, Ernesto Benito Salvatierra Izaba, Germán Martínez Velasco y Rosa Elva Zúñiga López (2000), "Determinantes socioeconómicos de la migración laboral: el caso de los indígenas mames de la Sierra Madre de Chiapas, México". En Papeles de Población, vol. 23, pp. 153-179.

Pohlenz Córdova, Juan (1995), Dependencia y desarrollo capitalista en la sierra de Chiapas. México: Centro de Investigaciones Humanísticas de Mesoamérica y el Estado de Chiapas, Universidad Nacional Autónoma de México.

Regino Montes, Adelfo (2002), "La comunalidad. Raíz, pensamiento, acción y horizonte de los pueblos indígenas". En México Indígena. Nueva Época, vol. 1, núm. 2, pp. 7-14.

Robledo Hernández, Gabriela (2010), "Vivir en frontera. Movimientos socio-religiosos en Chiapas y
Guatemala”. En LiminaR. Estudios Sociales y Humanísticos, vol. 8, núm. 2, pp. 182-190.

Salvatierra Izaba, Ernesto Benito (2000), "Desarrollo rural y población. El caso del Soconusco, Chiapas". Tesis de doctorado en Ciencias en Desarrollo Rural, Colegio de Postgraduados, Montecillo, Texcoco.

Turner, Frederick Jackson (1987), "La frontera en la historia americana, 1894". En Secuencia. Revista Americana de Ciencias Sociales, enero-abril, pp. 186-207.

Villalba Sánchez, Rodolfo (200la), "Tres comunidades de Chiapas crean municipio autónomo”. En La Jornada, 13 de marzo de 2001, México.

Villalba Sánchez, Rodolfo (200lb), "Inicia Pavencul su independización”. En Diario del Sur, 13 de marzo de 2001, Tapachula, Chiapas, México. 
Gráfica 1. Mercado cambiario y dinámica comercial en el territorio mam

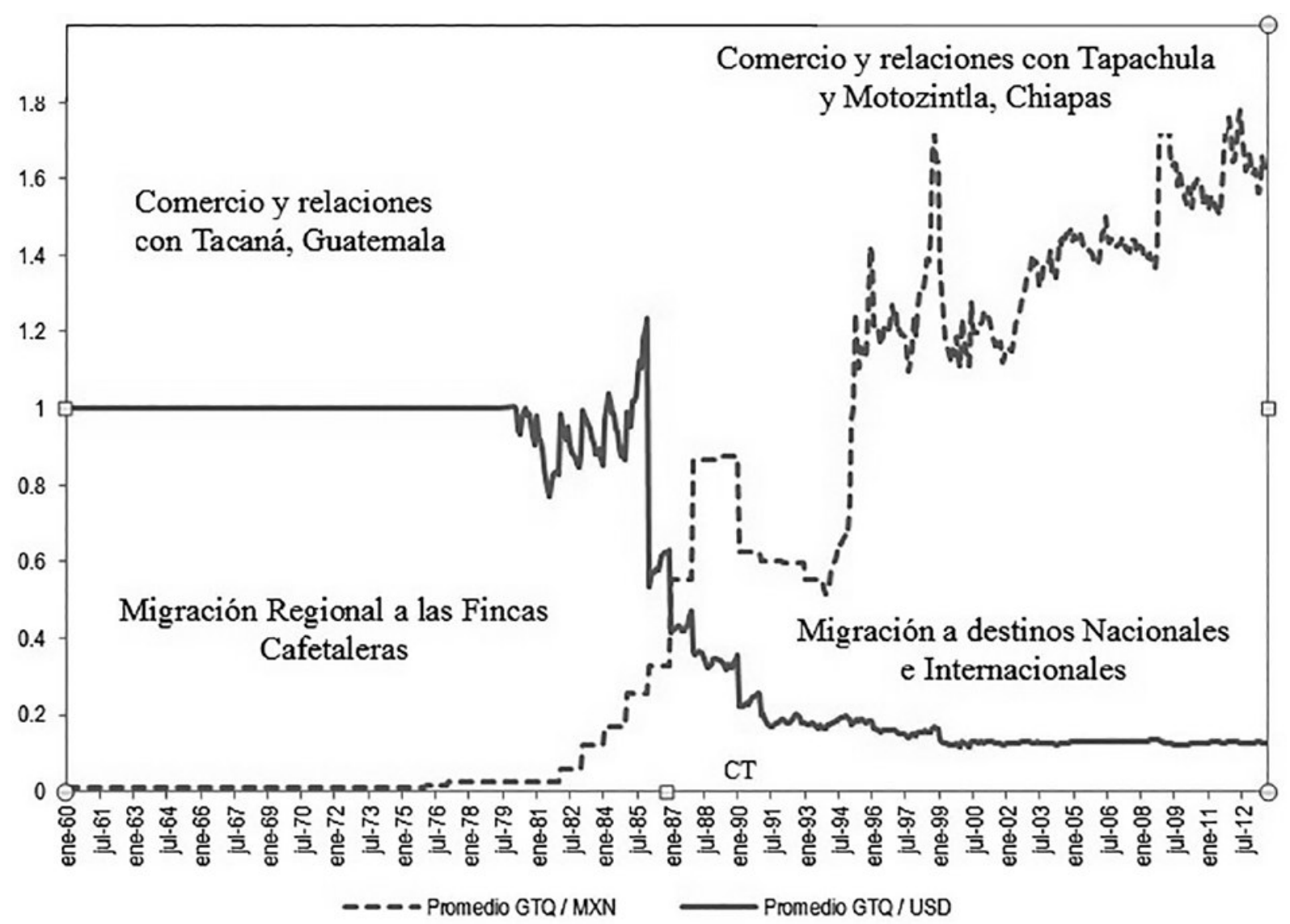

Fuente: elaborado con datos del Banco de México, agosto de 2013

Tipo de cambio del Quetzal frente al peso mexicano y dólar de EU 1960-2012. GTM: Quetzales de Guatemala, MXN: Moneda nacional de México, USD: Dólares de Estados Unidos, CT: Camino de Terracería en la Sierra 


\section{Mapa 1. Ubicación del ejido Pavencul y la zona mam}

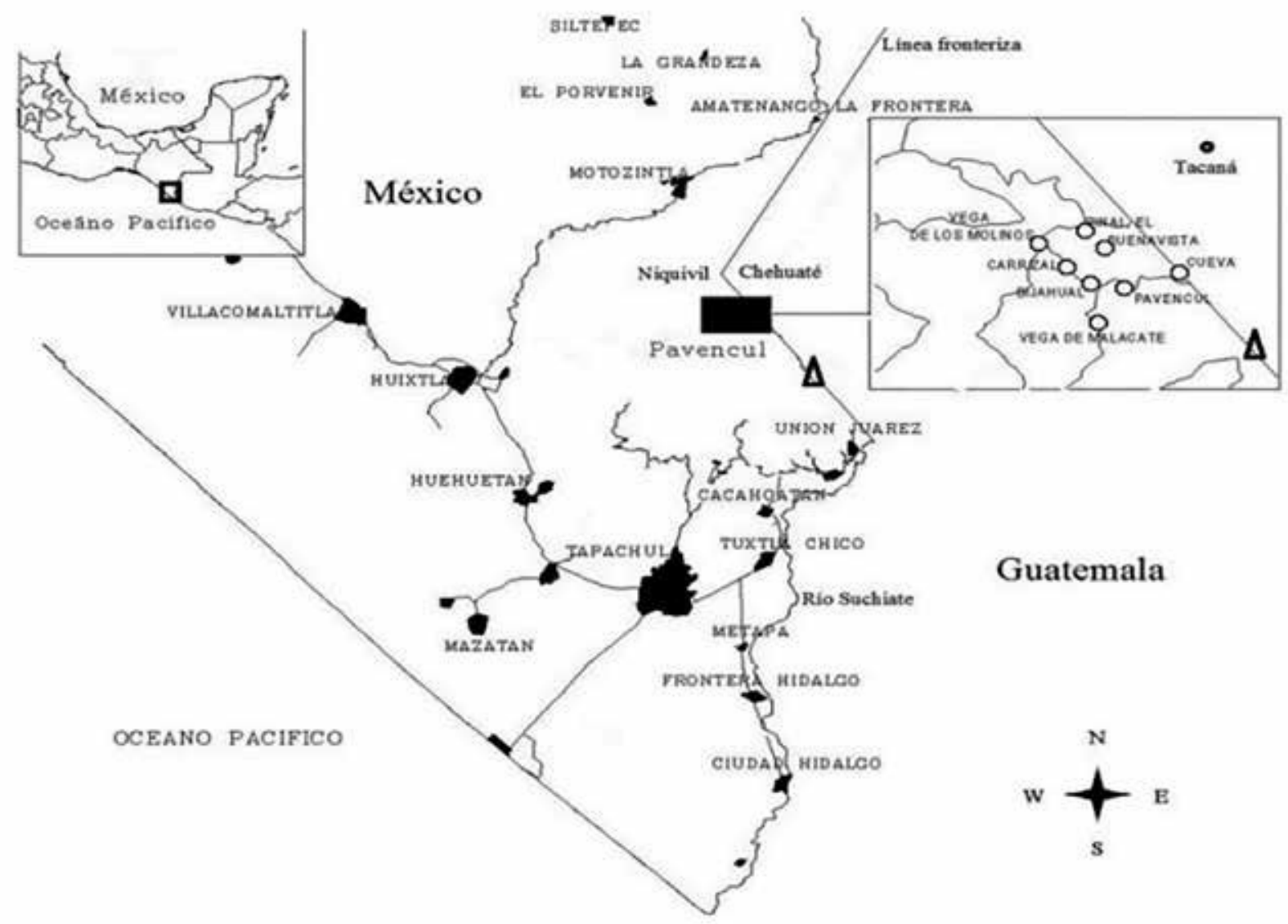

Fuente: Joaquín Peña Piña. Elaboración propia con datos de campo, 1998, 2002 y 2012. 


\section{Mapa 2. Migración laboral regional y extrarregional de Pavencul}

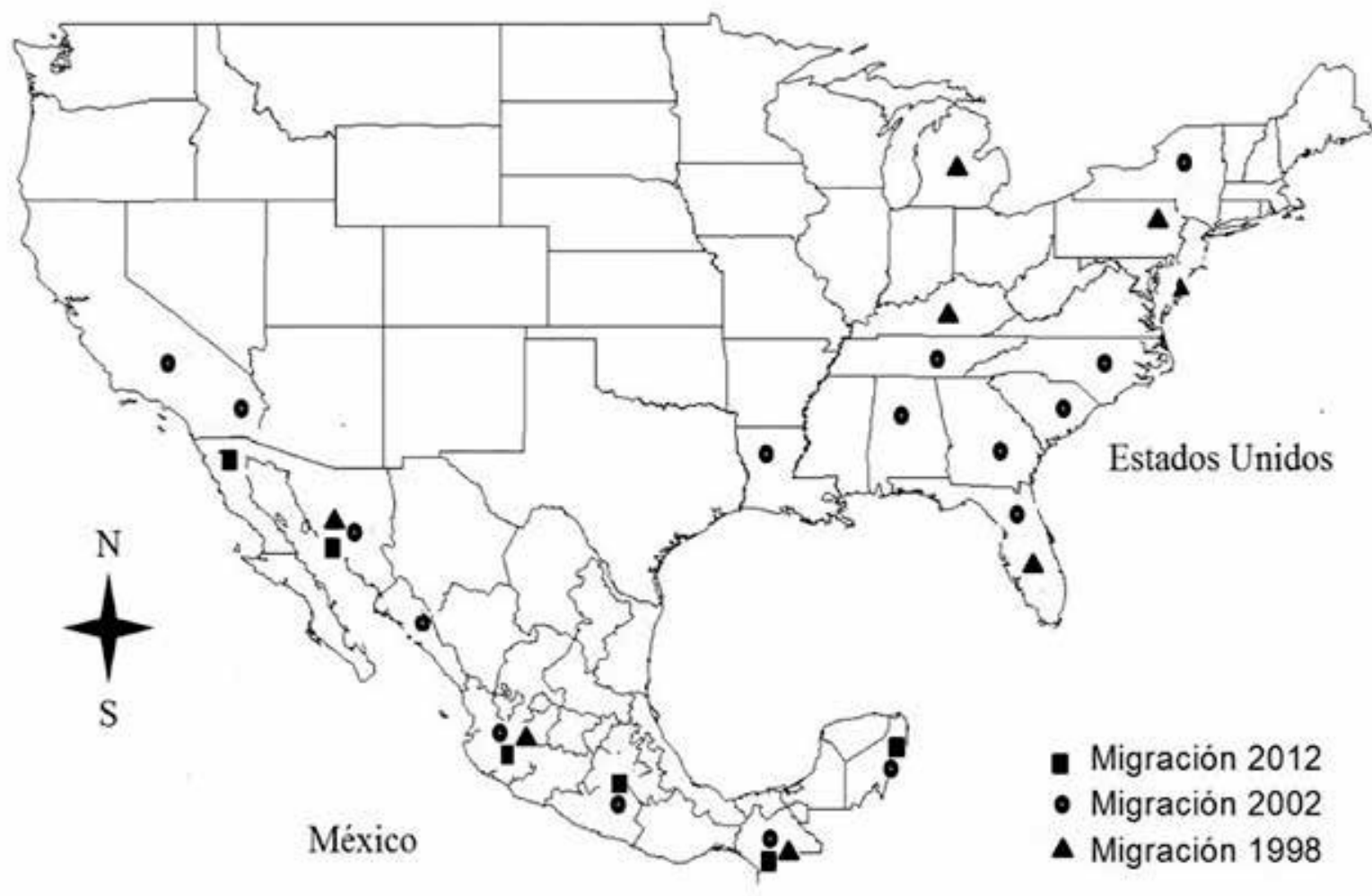

Fuente: Joaquín Peña Piña. Elaboración propia con datos de campo, 1998, 2002 y 2012. 